\begin{tabular}{|c|c|c|}
\hline \multirow{3}{*}{$\begin{array}{r}\text { Case Reports in } \\
\text { Gastroenterology }\end{array}$} & \multirow{2}{*}{\multicolumn{2}{|c|}{ Case Rep Gastroenterol 2013;7:503-510 }} \\
\hline & & \\
\hline & $\begin{array}{l}\text { DOI: } 10.1159 / 000357304 \\
\text { Publisned online: November 28, } 2013\end{array}$ & $\begin{array}{l}\text { (c) } 2013 \text { S. Karger AG, Basel } \\
1662-0631 / 13 / 0073-0503 \$ 38.00 / 0 \\
\text { www.karger.com/crg }\end{array}$ \\
\hline & \multicolumn{2}{|c|}{$\begin{array}{l}\text { This is an Open Access article licensed under the terms of the Creative Commons } \\
\text { Attribution-NonCommercial } 3.0 \text { Unported license (CC BY-NC) (www.karger.com/OA- } \\
\text { license), applicable to the online version of the article only. Distribution permitted for non- } \\
\text { commercial purposes only. }\end{array}$} \\
\hline
\end{tabular}

\title{
A Large Hepatic Cyst with Obstructive Jaundice Successfully Treated with Single-Incision Laparoscopic Deroofing
}

\author{
Hajime Imamura $^{a} \quad$ Yujo Kawashita ${ }^{a} \quad$ Naoki Koga $^{a} \quad$ Yuichi Sanada $^{a}$ \\ Takashi Azuma $^{a}$ Shigetoshi Matsuo ${ }^{a}$ Susumu Eguchib \\ ${ }^{a}$ Department of Surgery, Shimabara Hospital, Shimabara, and ${ }^{b}$ Department of Surgery, \\ Nagasaki University Graduate School of Biomedical Sciences, Nagasaki, Japan
}

\section{Key Words}

Hepatic cyst · Single-incision laparoscopic surgery · Jaundice

\begin{abstract}
We herein present a case of hepatic cysts causing obstructive jaundice that was treated with single-incision laparoscopic deroofing. A 72-year-old female patient was referred to hospital due to a large hepatic cyst that compressed the intrahepatic bile ducts. The patient was scheduled to undergo single-incision laparoscopic deroofing. The EZ ACCESS ${ }^{\mathrm{TM}}$ oval type (Hakko Co. Ltd.) was placed at the umbilicus using a $25-\mathrm{mm}$ incision with two 5-mm trocars. An additional $12-\mathrm{mm}$ port was placed at the left epigastric region. We unroofed and excised the cyst wall using a vessel sealing system in liver segment 4. After surgery, the patient was found to be asymptomatic. The unroofed cysts were completely diminished. Notably, the remnant liver had fairly regenerated. The estimated regeneration volume of the normal liver was $153 \mathrm{~cm}^{3}$. To prevent surgical complications, clinicians should perform adequate management and use of devices. To prevent postoperative recurrence of cysts, performing complete deroofing is essential. Single-incision laparoscopic deroofing contributes to improving the quality of life of patients and should be considered a standard treatment.
\end{abstract}


Imamura et al.: A Large Hepatic Cyst with Obstructive Jaundice Successfully Treated with Single-Incision Laparoscopic Deroofing

\section{Introduction}

Simple hepatic cysts are congenital liver diseases. They are usually found incidentally during radiographic examinations conducted for other purposes. In most cases they are asymptomatic, and no treatment is required. However, the clinical manifestations of liver cysts occasionally include compression of the liver parenchyma with jaundice, portal hypertension, abdominal pain, hemorrhage and rupture. These symptomatic cysts can be an indication for treatment. Major treatment options include ultrasound-guided aspiration and laparoscopic deroofing. Previous reports have shown that simple aspiration can be associated with a high recurrence rate [1-3]. Therefore, deroofing of hepatic cysts is the most popular surgical procedure. Before the introduction of laparoscopic surgery, open deroofing was regarded to be the standard method to treat symptomatic liver cysts. With the development of surgical devices and skills, laparoscopic deroofing has produced better results with minimal invasion. Recently, the use of single-incision laparoscopic surgery [4] has been applied to hepatobiliary and digestive surgery. Although it is a technically demanding procedure, its clinical benefits, related to less invasiveness, far outweigh its disadvantages.

This report presents the case of a large hepatic cyst with intrahepatic obstructive jaundice that was successfully treated with single-incision laparoscopic deroofing.

\section{Case Report}

A 72-year-old female patient was referred to our hospital due to right upper abdominal pain. Physical examination performed on admission revealed mild tenderness in the right epigastrium. Laboratory data revealed a serum bilirubin level of $1.6 \mathrm{mg} / \mathrm{dl}$, an aspartate aminotransferase level of $226 \mathrm{IU} / \mathrm{l}$, an alanine aminotransferase level of $164 \mathrm{IU} / \mathrm{l}$ and an alkaline phosphate level of 1,062 IU/l. A computed tomography (CT) scan disclosed two large hepatic cysts at segment 4 measuring $86 \times 112 \times 115 \mathrm{~mm}$ (fig. 1a) and $39 \times 45 \times 40$ $\mathrm{mm}$ (fig. 1b), respectively. In addition, the intrahepatic bile ducts were slightly dilated due to compression of the hepatic hilum. Magnetic resonance cholangiopancreatography (MRCP) also showed intrahepatic duct dilatation (fig. 2), although no communications between the cysts and the intrahepatic bile ducts were detected. Based on these findings, the provisional diagnosis was a symptomatic large hepatic cyst with compression of the intrahepatic bile duct. The patient was scheduled to undergo laparoscopic deroofing.

The patient was placed in the supine position and an entry hole into the abdomen was created using an umbilical incision $(25 \mathrm{~mm})$. The EZ ACCESS ${ }^{\mathrm{TM}}$ oval type (Hakko Co. Ltd.; fig. 3 ) was placed at the umbilicus using a $25-\mathrm{mm}$ incision as an access port with two $5-\mathrm{mm}$ trocars. An additional 12-mm port was placed at the left epigastric region (fig. 4). Cysts were detected in liver segment 4 . A small incision was made in the cyst using an ultrasonically activated device, and serous fluid was evacuated. A vessel sealing system (Ligasure; Covidien, Mansfield, Mass., USA) was then used to excise the cyst wall. A thick peripheral bile duct was identified and clipped.

The patient's postoperative course was uneventful, and she was discharged on postoperative day 8. The pathological findings revealed a solitary cyst without malignant transformation. Four months after surgery, no recurrent symptoms were observed and liver regeneration was detected on abdominal CT. The regeneration volume of the liver was 153 $\mathrm{cm}^{3}$ (fig. 5). 
Imamura et al.: A Large Hepatic Cyst with Obstructive Jaundice Successfully Treated with Single-Incision Laparoscopic Deroofing

\section{Discussion}

Hepatic cysts are common liver diseases. Generally, they are asymptomatic without the need for treatment such as percutaneous drainage or surgery. The reported symptoms of liver cysts include jaundice, pain and cyst rupture due to compression of adjacent structures. Cysts are often found incidentally during radiologic examinations. CT and magnetic resonance imaging are useful for precisely diagnosing hepatic cysts and planning surgical treatment. In particular, MRCP is helpful for confirming the conditions of biliary compression in cases of obstructive jaundice. MRCP can also be used to assess communications between the lesion and the intrahepatic bile ducts. However, the efficacy of such modalities remains unknown [5].

Symptomatic cysts can be an indication for surgical intervention. Treatment of hepatic cysts can be divided into two categories: percutaneous aspiration and surgical procedures. Percutaneous aspiration can be used to quickly relieve the patient's symptoms. However, previous reports have shown that simple aspiration is associated with a high recurrence rate of $75-100 \%$ [1-3]. In addition, percutaneous aspiration can cause leakage of cyst fluid, deviation of the drainage tube and adhesion between the cyst and the peritoneum, which can become an obstacle during surgery. Compared with the percutaneous approach, surgical procedures have a benefit in terms of postoperative recurrence. Currently, deroofing of hepatic cysts, first described by Lin et al. in 1968 [6], is the most popular surgical procedure. Before the introduction of laparoscopic surgery, open deroofing was regarded to be the standard method of treating symptomatic liver cysts. With developments in surgical devices and skills, laparoscopic deroofing has come to produce preferable results with minimal invasion. Qiu et al. [7] reported that the short-term outcomes of laparoscopic deroofing are superior to open methods with respect to postoperative complications and cyst recurrence rates.

Recently, the use of single-incision laparoscopic surgery, as reported by Navarra et al. [4], has been applied to the liver, colon and pancreas. Initially, standard laparoscopic deroofing was usually performed with four trocars [8]. In our case, the access port was placed at the umbilicus through a $25-\mathrm{mm}$ incision. The umbilical scar eventually became invisible (fig. 6). We used a 12-mm trocar at the left epigastric region from the beginning in order to manage unexpected events during surgery, for example bleeding or injury to the exposed peripheral bile ducts. While cosmetic advantages are important for patients, adequate consideration should be given to secure the safety of the surgical procedure. To prevent surgical complications such as bile duct injury and hemorrhage, clinicians should perform adequate management and use of devices. If the presence of an exposed peripheral bile duct on the surface of the lumen is confirmed, clipping of the bile duct should be performed to prevent postoperative bile leakage (fig. 7).

To prevent postoperative recurrence of cysts, performing complete deroofing is essential. In order to completely excise the cyst wall in this case, we used the Ligasure, which exhibits better sealing effects than ultrasonic shears. Devices such as the Ligasure are useful for achieving hemostasis, and appropriate selection of devices is related to safe and effective procedures. In cases of cysts located in S7 and S8 or near the left subphrenic area, deroofing of the cysts with mobilization of the right liver lobe and proper omentum placement are important for preventing 'adhesive' cyst recurrence. The cyst edge can adhere to surrounding tissue and become fixed, leading to loss of movement around the diaphragm or peritoneum in the absence of mobilization.

In our case, the liver volume was increased and the original cyst cavity was found to be replaced by normal hepatic parenchyma on postoperative CT (fig. 5). We have previously 
Imamura et al.: A Large Hepatic Cyst with Obstructive Jaundice Successfully Treated with Single-Incision Laparoscopic Deroofing

reported that such liver regeneration can be observed following deroofing of large liver cysts in response to the loss of occupied space in the absence of shear stress $[9,10]$. In the future, newly developed devices, as well as robotic surgery, may further facilitate the use of reduced port surgery for treating hepatic cysts.

\section{Conclusion}

Reduced port surgery, including single-incision laparoscopic deroofing, is believed to contribute to improving the quality of life of patients and should be considered a standard treatment for patients with symptomatic hepatic cysts.

\section{Disclosure Statement}

None of the authors have any conflicts of interest to declare. This work was not funded by any educational or commercial organization, and no commercial organization was involved in the preparation of any part of this article.

\section{References}

1 Mazza OM, Fernandez DL, Pekolj J, Pfaffen G, Sanchez Clariá R, Molmenti EP, de Santibañes E: Management of nonparasitic hepatic cysts. J Am Coll Surg 2009;209:733-739.

-2 Saini S, Mueller PR, Ferrucci JT Jr, Simeone JF, Wittenberg J, Butch RJ: Percutaneous aspiration of hepatic cysts does not provide definitive therapy. AJR Am J Roentgenol 1983;141:559-560.

-3 Gigot JF, Legrand M, Hubens G, de Canniere L, Wibin E, Deweer F, Druart ML, Bertrand C, Devriendt H, Droissart R, Tugilimana M, Hauters P, Vereecken L: Laparoscopic treatment of nonparasitic liver cyst: adequate selection of patients and surgical technique. World J Surg 1996;20:556-561.

4 Navarra G, Pozza E, Occhionorelli S, Carcoforo P, Donini I: One-wound laparoscopic cholecystectomy. Br J Surg 1997;84:695.

5 Fong ZV, Wolf AM, Doria C, Berger AC, Rosato EL, Palazzo F: Hemorrhagic hepatic cyst: report of a case and review of the literature with emphasis on clinical approach and management. J Gastrointest Surg 2012;16:1782-1789.

-6 Lin TY, Chene CC, Wang SM: Treatment of non-parasitic cystic disease of the liver; a new approach to therapy with polycystic liver. Ann Surg 1968;168:921-927.

7 Qiu JG, Wu H, Jiang H, Huang JW, Pankaj P, Xu YL, Wang JZ, Zeng Y: Laparoscopic fenestration versus open fenestration in patients with congenital hepatic cysts: a meta-analysis. World J Gastroenterol 2011;17:3359-3365.

8 Morino M, De Giuli M, Festa V, Garrone C: Laparoscopic management of symptomatic nonparasitic cysts of the liver. Ann Surg 1994;219:157-164.

>9 Miyazaki K, Eguchi S, Tomonaga T, Inokuma T, Hamasaki K, Yamanouchi K, Takatsuki M, Kamohara Y, Tajima Y, Kanematsu T: The impact of the intra-abdominal space on liver regeneration after a partial hepatectomy in rats. J Surg Res 2011;171:259-265.

10 Eguchi S, Siogama T, Tsurunaga Y, Mizutani A, Furui J, Kanematsu T, Fukui H: The effect of fenestration procedure on liver regeneration in a case of polycystic liver disease. Hepatogastroenterology 2001;48:1733-1735. 


\section{Case Reports in \\ Gastroenterology}

\begin{tabular}{l|l}
\hline Case Rep Gastroenterol 2013;7:503-510 \\
\hline DOI: 10.1159/000357304 & $\begin{array}{l}\text { @ 2013 S. Karger AG, Basel } \\
\text { www.karger.com/crg }\end{array}$ \\
\hline
\end{tabular}

Imamura et al:: A Large Hepatic Cyst with Obstructive Jaundice Successfully Treated with Single-Incision Laparoscopic Deroofing
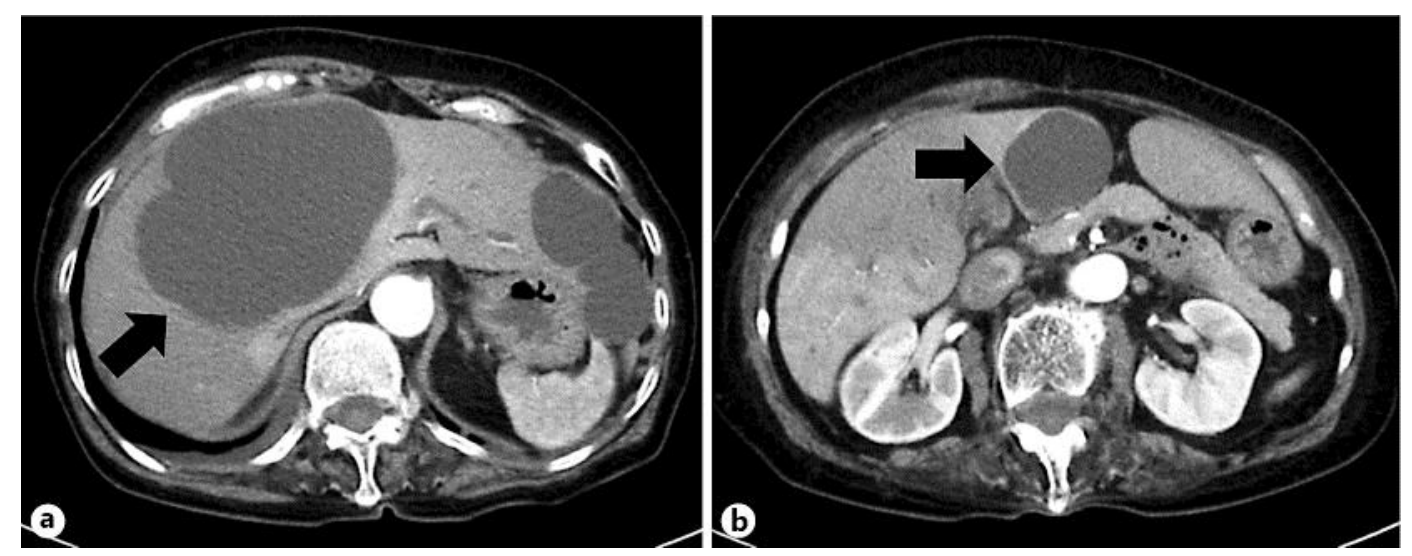

Fig. 1. Preoperative CT showed two large hepatic cysts in segment 4 measuring $86 \times 112 \times 115 \mathrm{~mm}$ (a; arrow) at the upper side and $39 \times 45 \times 40 \mathrm{~mm}$ (b; arrow) at the lower side of the segment.

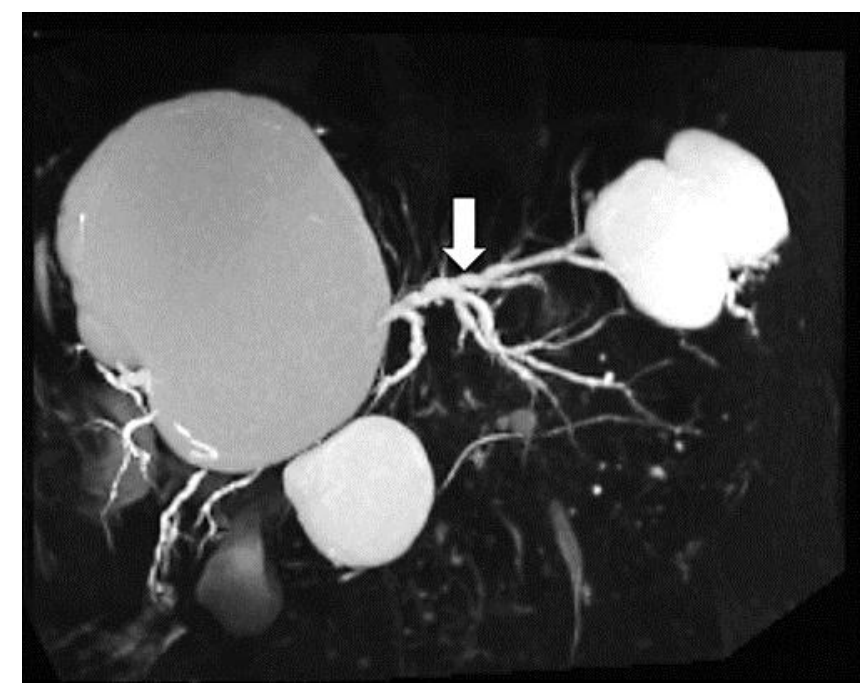

Fig. 2. Preoperative MRCP showed intrahepatic duct dilatation (arrow). 
Imamura et al.: A Large Hepatic Cyst with Obstructive Jaundice Successfully Treated with Single-Incision Laparoscopic Deroofing

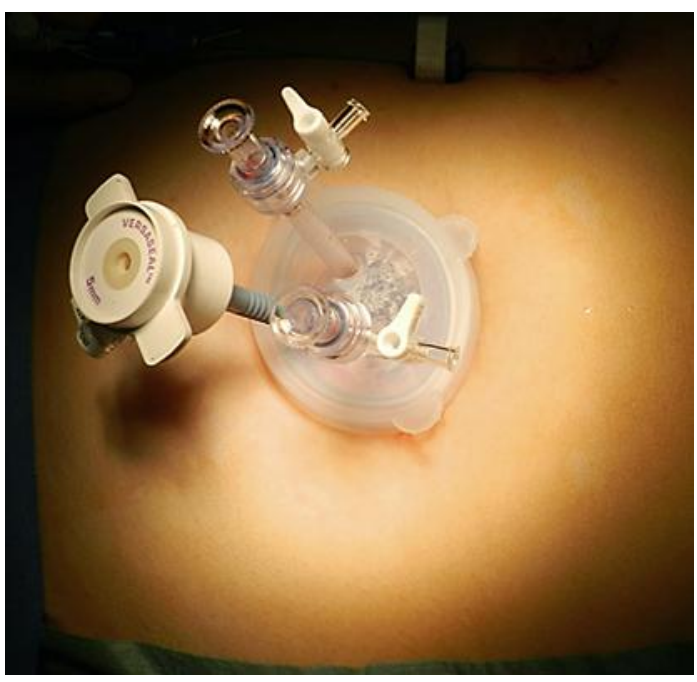

Fig. 3. The EZ ACCESSTM oval type (Hakko Co. Ltd.) was placed at the umbilicus.

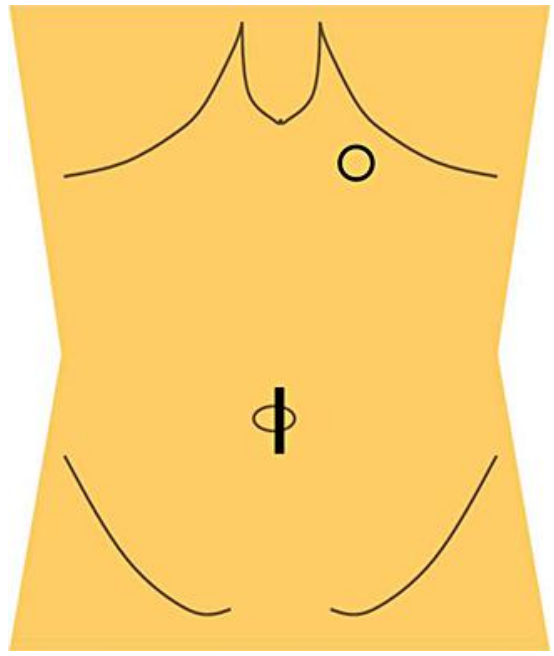

Fig. 4. As a platform, the EZ ACCESSTM with two 5-mm trocars was placed at the umbilicus using a 25-mm incision (black line). An additional 12-mm port was placed at the left epigastric region (circle). 
Imamura et al:: A Large Hepatic Cyst with Obstructive Jaundice Successfully Treated with Single-Incision Laparoscopic Deroofing
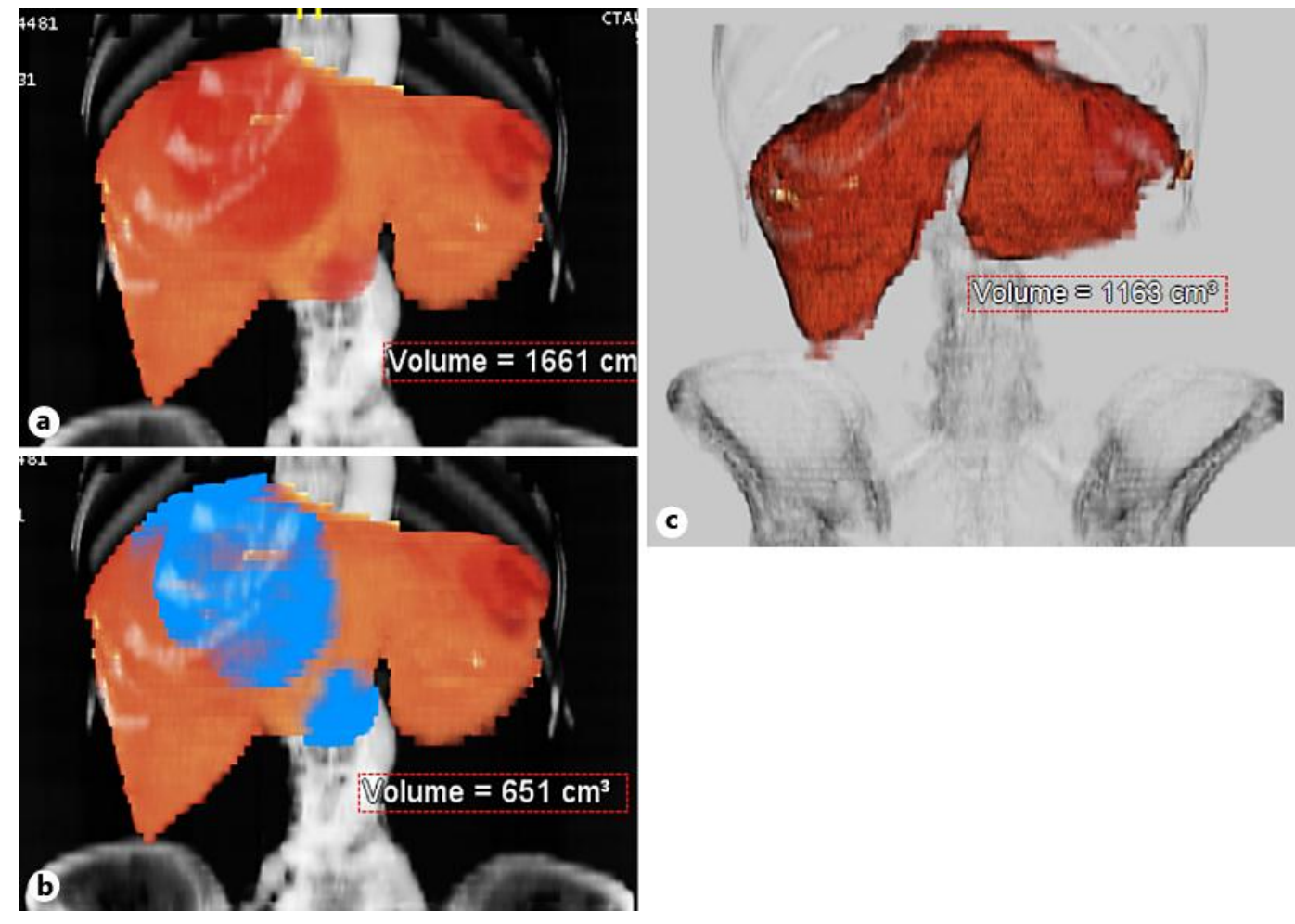

Fig. 5. Pre- and postoperative volume of the liver. a Preoperative whole liver volume: 1,661 $\mathrm{cm}^{3}$. b Preoperative cystic lesions (blue lesions): $651 \mathrm{~cm}^{3}$. c Postoperative whole liver: 1,163 $\mathrm{cm}^{3}$. The regeneration volume of the liver $[\mathbf{c}-(\mathbf{a}-\mathbf{b})]$ was $153 \mathrm{~cm}^{3}$.

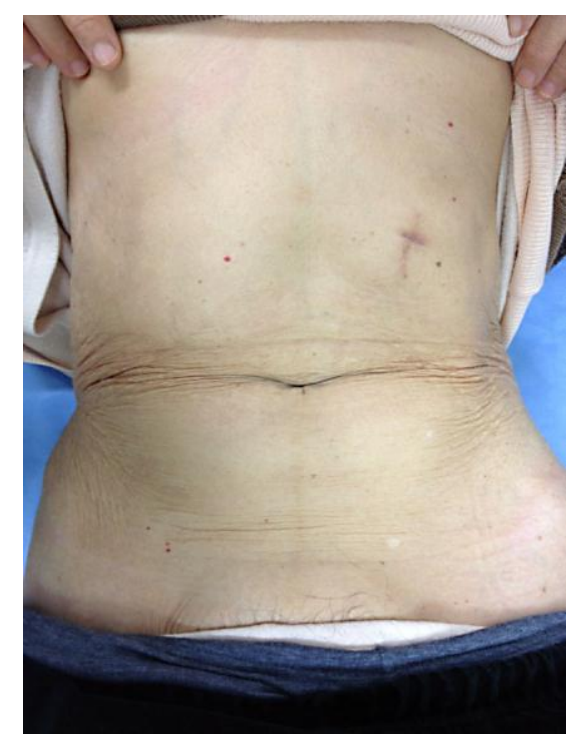

Fig. 6. The postoperative umbilical scar became inconspicuous during the healing process. 
Imamura et al.: A Large Hepatic Cyst with Obstructive Jaundice Successfully Treated with Single-Incision Laparoscopic Deroofing

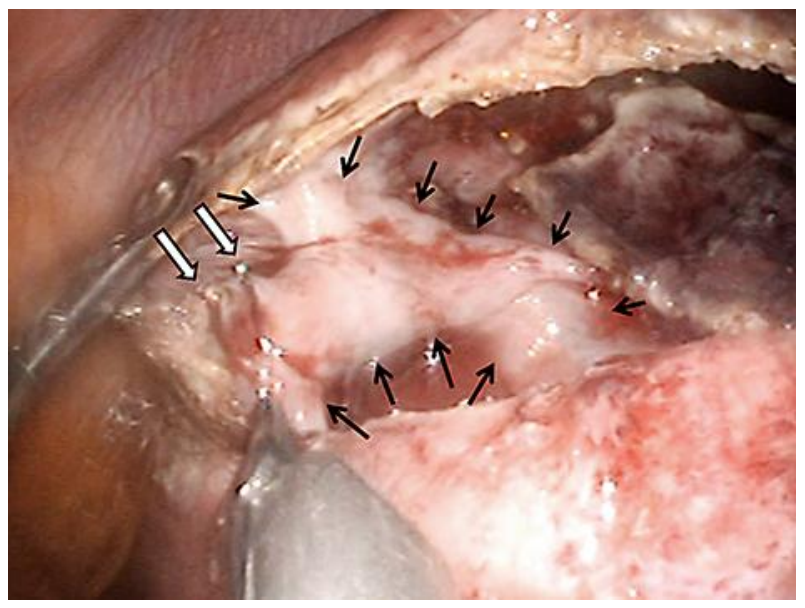

Fig. 7. An exposed peripheral bile duct (black arrows) was clipped (white arrows). 